\title{
Contaminant Removal from Oxygen Production Systems for In Situ Resource Utilization
}

\author{
Stephen M. Anthony ${ }^{1}$ and Edgardo Santiago-Maldonado ${ }^{2}$ \\ National Aeronautics and Space Administration, John F. Kennedy Space Center, Florida 32899 \\ James G. Captain ${ }^{3}$ \\ QinetiQ North America, John F. Kennedy Space Center, Florida 32899 \\ Ashtamurthy S. Pawate ${ }^{4}$ and Paul J.A. Kenis ${ }^{5}$ \\ University of Illinois at Urbana-Champaign, Urbana, Illinois 61801
}

$\begin{array}{ll}A & \\ A & =\text { membrane contact area, } \mathrm{cm}^{2} \\ C_{i}{ }^{G} & =\text { gas-side concentration of } i \text { in water, } \mathrm{ppm} \\ C_{i}{ }^{L} & =\text { liquid-side concentration of } i \text { in water, } \mathrm{ppm} \\ m & =\text { mass of acid solution collected, } \mathrm{g} \\ J_{i} & =\text { mass flux of } i, \mathrm{~g} / \mathrm{cm}^{2} \cdot \min \\ p\left(T_{i}\right) & =\text { vapor pressure of water at temperature } T_{i}, \text { torr } \\ Q & =\text { gas flow rate, } \mathrm{L} / \mathrm{min} \\ R_{i} & =\text { membrane rejection fraction of } i \\ t & =\text { sample collection time, min } \\ T_{i} & =\text { temperature measurement at location } i,{ }^{\circ} \mathrm{C}\end{array}$

\begin{abstract}
$\mathrm{T}$ he In Situ Resource Utilization (ISRU) project has been developing technologies to produce oxygen from lunar regolith to provide consumables to a lunar outpost. The processes developed reduce metal oxides in the regolith to produce water, which is then electrolyzed to produce oxygen. Hydrochloic and hydrofluoric acids are byproducts of the reduction processes, as halide minerals are also reduced at oxide reduction conditions. Because of the stringent water quality requirements for electrolysis, there is a need for a contaminant removal process. The Contaminant Removal from Oxygen Production Systems (CROPS) team has been developing a separation process to remove these contaminants in the gas and liquid phase that eliminates the need for consumables. CROPS has been using Nafion, a highly water selective polymeric proton exchange membrane, to recover pure water from the contaminated solution. Membrane thickness, product stream flow rate, and acid solution temperature and concentration were varied with the goal of maximizing water permeation and acid rejection. The results show that water permeation increases with increasing solution temperature and product stream flow rate, while acid rejection increases with decreasing solution temperature and concentration. Thinner membranes allowed for higher water flux and acid rejection than thicker ones. These results were used in the development of the hardware built for the most recent Mars ISRU demonstration project.
\end{abstract}

\section{Introduction}

The goal of In Situ Resource Utilization (ISRU) is to develop systems that allow for a long-term human presence in space without the need for replenishment of materials from Earth. Lunar regolith is of particular interest to ISRU researchers as potential source of oxygen for fuel and life support ${ }^{1,2}$. Hydrogen, which has been detected in the permanently-shaded regions of craters near the lunar poles, can be used to reduce the metal oxides present in lunar regolith to produce water, and via electrolysis, oxygen ${ }^{3,4}$.

${ }^{1}$ Aerospace Technologist, Engineering and Technology Directorate, Mail Code NE-F2.

${ }^{2}$ Chemical Engineer, Engineering and Technology Directorate, Mail Code NE-S.

${ }^{3}$ Chemist, Applied Science and Technology, Mail Code ESC-55.

${ }^{4}$ Post-Doctoral Associate, Department of Chemical and Biomolecular Engineering, MC-712, 600 S. Mathews Ave.

${ }^{5}$ Professor, Department of Chemical and Biomolecular Engineering, MC-712, 600 S. Mathews Ave.

American Institute of Aeronautics and Astronautics 
Prior to electrolysis, the water generated as an intermediate product must be treated to remove absorbed hydrochloric and hydrofluoric acids, byproducts derived from trace amounts of fluoride and chloride present in lunar regolith $^{5}$. In terrestrial applications, removal of chloride and fluoride from water is a relatively trivial process due to the availability of consumable adsorbents, or by utilizing other processes that require frequent regeneration ${ }^{6-12}$. None of these processes are applicable in the lunar environment, however, where resources are scarce.

Nafion, a commercially-available sulfonated tetrafluoroethylene polymer membrane, is promising as an ISRU filtration material because it can continuously facilitate water transport and acid rejection without the need for replacement or regeneration.. Water diffuses through Nafion via sulfonic acid-lined channels ${ }^{13,14}$, and anions are rejected due to the negative potential of those water channels ${ }^{15}$. We investigated the effect of several variables on water flux and chloride and fluoride anion rejection in an effort to develop an in situ contaminant removal system for lunar regolith-derived water.

\section{Experimental}

\section{A. Experimental Apparatus}

Fig. 1 is a schematic representation of the apparatus used for all experiments. Nafion membranes were secured between two poly(tetrofluoroethylene) (PTFE) plates with a wetted area of $39.6 \mathrm{~cm}^{2}$. All components that contacted the hydrochloric (Fisher) and hydrlofluoric (Sigma-Aldrich) acid solution were made from PTFE to prevent corrosion and contamination. The acid solution temperature was maintained by controlling the hot plate and heater settings on the circulating water bath.

Nafion NR-212, N115 and N1110 membranes (Ion Power) having thicknesses of 51 $\mu \mathrm{m}, 127 \mu \mathrm{m}$ and $254 \mu \mathrm{m}$ respectively, were tested for their ability to reject chloride and fluoride while allowing transport of water. Solutions containing 10000 parts per million (ppm) by mass of $\mathrm{HCl}$ and $\mathrm{HF}$ in deionized water were continuously pumped across one side of the membrane at temperatures of 20,40 , and $60^{\circ} \mathrm{C}$. Dry nitrogen gas at approximately $50 \mathrm{psig}$ was passed across the other side of the membrane at flow rates between 1 and $5 \mathrm{~L} / \mathrm{min}$ in $1 \mathrm{~L} / \mathrm{min}$ increments, maintained by a mass flow controller (MKS). The water and acid vapor that diffused across the membrane was then condensed in a glycol bath held at $0{ }^{\circ} \mathrm{C}$. Collection times varied depending on the solution temperature, and were typically $15-30 \mathrm{~min}$ per run at $60^{\circ} \mathrm{C}, 30-45 \mathrm{~min}$ at $40^{\circ} \mathrm{C}$, and $60-90 \mathrm{~min}$ at $20^{\circ} \mathrm{C}$.

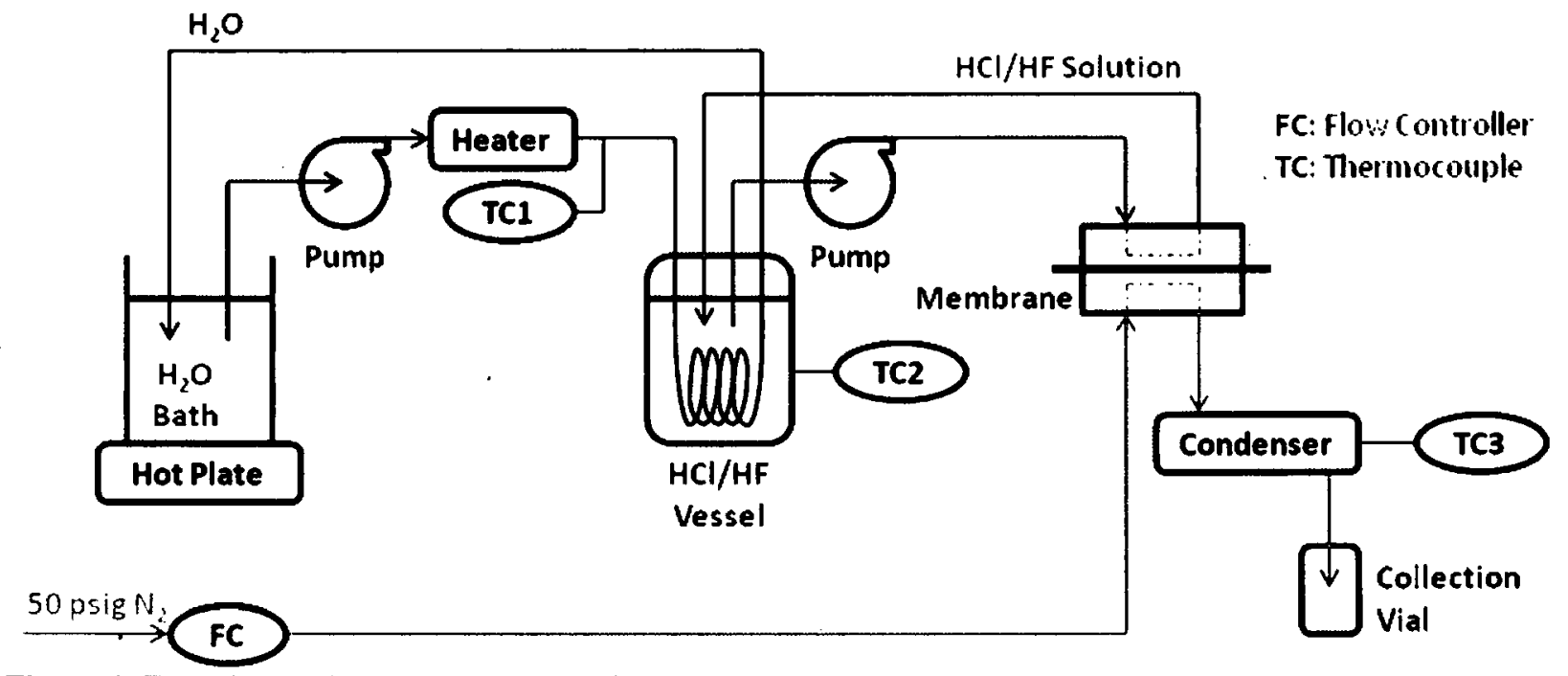

Figure 1. Experimental apparatus schematic. 


\section{B. Water and Acid Permeation}

The molar water flux $\left(J_{w}\right)$ was calculated as a function of the mass of water collected $(m)$ across the membrane cross-sectional area $(A)$ over time $(t)$. To account for the theoretical mass of water vapor not condensed, the molar flux was adjusted based on the water vapor pressure $(p)$ at temperatures at the membrane $\left(T_{m}\right)$ and the condenser outlet $\left(T_{c}\right)$, as described by Eq. (1):

$$
J_{w}=\frac{m}{A \cdot t} \cdot \frac{p\left(T_{m}\right)}{p\left(T_{m}\right)-p\left(T_{c}\right)}
$$

The concentration of chloride and fluoride ions in the collected samples $\left(C_{i}^{G}\right)$ were measured using the Dionex LC20 Ion Chromatograph, and compared to the starting concentration $\left(C_{i}^{L}\right)$ to determine the rejection fractions $\left(R_{i}\right)$ of chloride and fluoride using Eq. (2):

$$
R_{i}=1-\frac{C_{i}^{G}}{C_{i}^{L}}
$$

\section{Results and Discussion}

\section{A. Water Flux}

Water flux across Nafion membranes as a function of solution temperature and gas-side nitrogen flow rate is reported in Fig. 2 as a function of nitrogen flow rate, water temperature, and membrane thickness. The data shown depict water flux as a function of solution temperature for the $51 \mu \mathrm{m}$ thick NR212 membrane (a), and as a function of membrane thickness at a solution temperature of $60^{\circ} \mathrm{C}(\mathrm{b})$.

The data show that water flux increases with increasing nitrogen flow rate under all conditions. The water flux at $40{ }^{\circ} \mathrm{C}$ is approximately double the water flux at 20 ${ }^{\circ} \mathrm{C}$; likewise, water flux increases three to five times when increasing from $40{ }^{\circ} \mathrm{C}$ to 60 ${ }^{\circ} \mathrm{C}$. Water flux across the $51 \mu \mathrm{m}$ membrane was approximately $30 \%$ higher than across the $127 \mu \mathrm{m}$ membrane, and $50-100 \%$ higher than across the $254 \mu \mathrm{m}$ membrane. These results are consistent with previous studies ${ }^{13}$. While water flux increased significantly with increasing gas flow rate, the mass of water per volume of gas in the product stream decreased significantly. It is possible that higher gas flow rates cool the gas side of the membrane, decreasing the water permeation efficiency.

Figure 2. Water flux as a function of temperature, membrane thickness nitrogen flow rate. Results are shown for the NR-212 membrane (51 $\mathrm{\mu m}$ thick) as a function of temperature (a), and at $60^{\circ} \mathrm{C}$ as a function of membrane thickness (b).

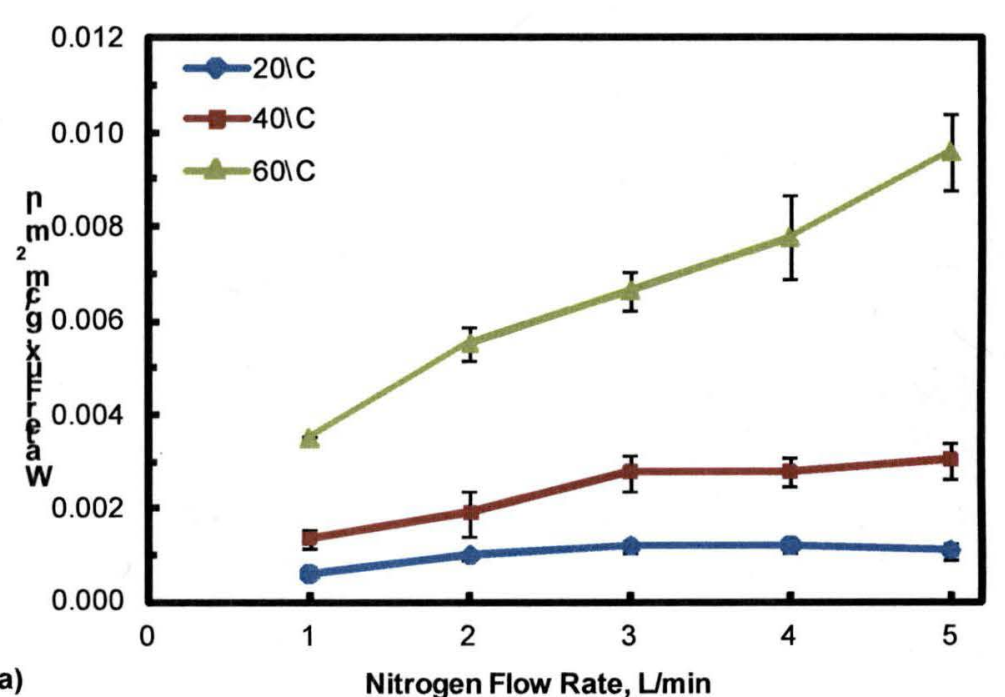

a)

Nitrogen Flow Rate, Lmin

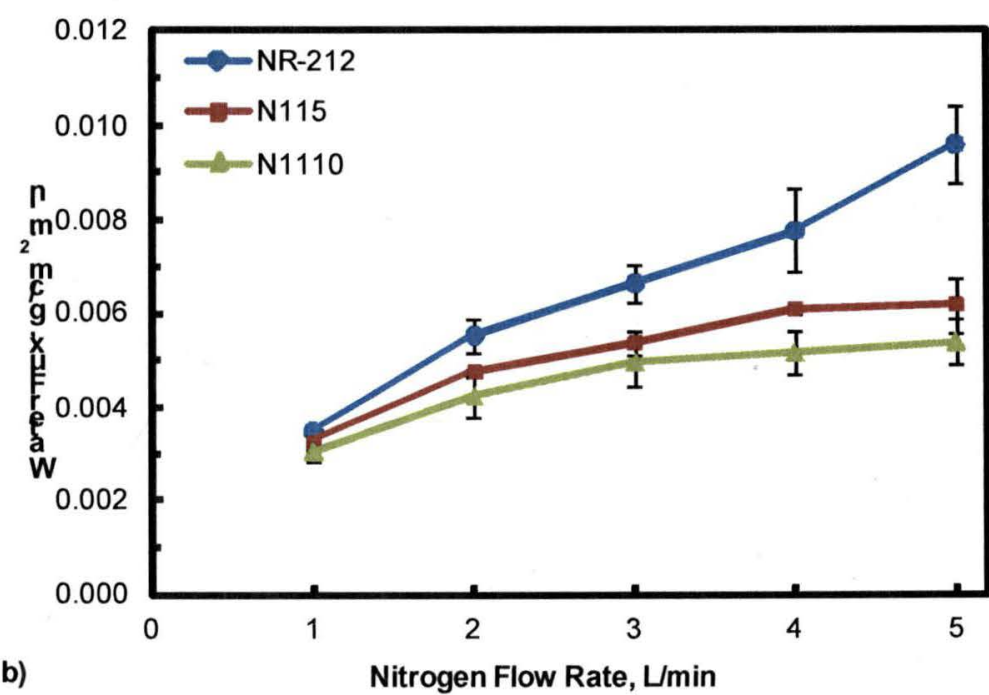

3

American Institute of Aeronautics and Astronautics 


\section{B. Anion Rejection}

The effects of membrane thickness and liquid-side solution temperature on chloride (a) and fluoride (b) rejection are shown in Fig. 3. At acid solution concentrations of 1000 or $10000 \mathrm{ppm}$, chloride rejection was very high for all membranes tested, at least $98 \%$ but most often ranging between 99.0 and $99.9 \%$. No correlation between chloride rejection and membrane thickness and acid solution temperature was observed. Fluoride rejection increased slightly with increasing temperature, ranging between 55 and $70 \%$ at $20{ }^{\circ} \mathrm{C}$, and between 70 and $85 \%$ at $60{ }^{\circ} \mathrm{C}$. Decreases in fluoride rejection were observed with increasing membrane thickness at all temperatures.

The high rejection of fluoride and particularly chloride can be attributed to charge exclusion. The channels through which water diffuses in Nafion membranes are lined with sulfonic acid end groups, and when the membrane is soaked in water, the diffusion of protons out of the membrane leave a negative potential in the water channels ${ }^{15,16} . \mathrm{HCl}$ is a strong acid $\left(p K_{a} \sim 7\right)$ and fully dissociates in water, so the negative potential of the membrane channels almost completely inhibits diffusion of chloride across the membrane. Since HF is a weak acid that only partially dissociates in water $\left(p K_{a}=3.17\right)^{17}$, permeation of undissociated HF is not as inhibited by the negative potential of the water channels as dissociated anions, resulting in lower expected fluoride rejection relative to chloride rejection.

The increase in fluoride rejection with increasing temperature may be due to swelling of water channels with increasing temperature, resulting in an increase in proton diffusion out of the water channels. This increased proton diffusion would thereby increase the negative potential of the water channels and further inhibit anion diffusion. Similarly, the decrease in fluoride rejection with increasing membrane thickness may be due to less efficient proton diffusion out of the water channels of thicker membranes, which would decrease the negative potential of the water channels and promote anion diffusion.
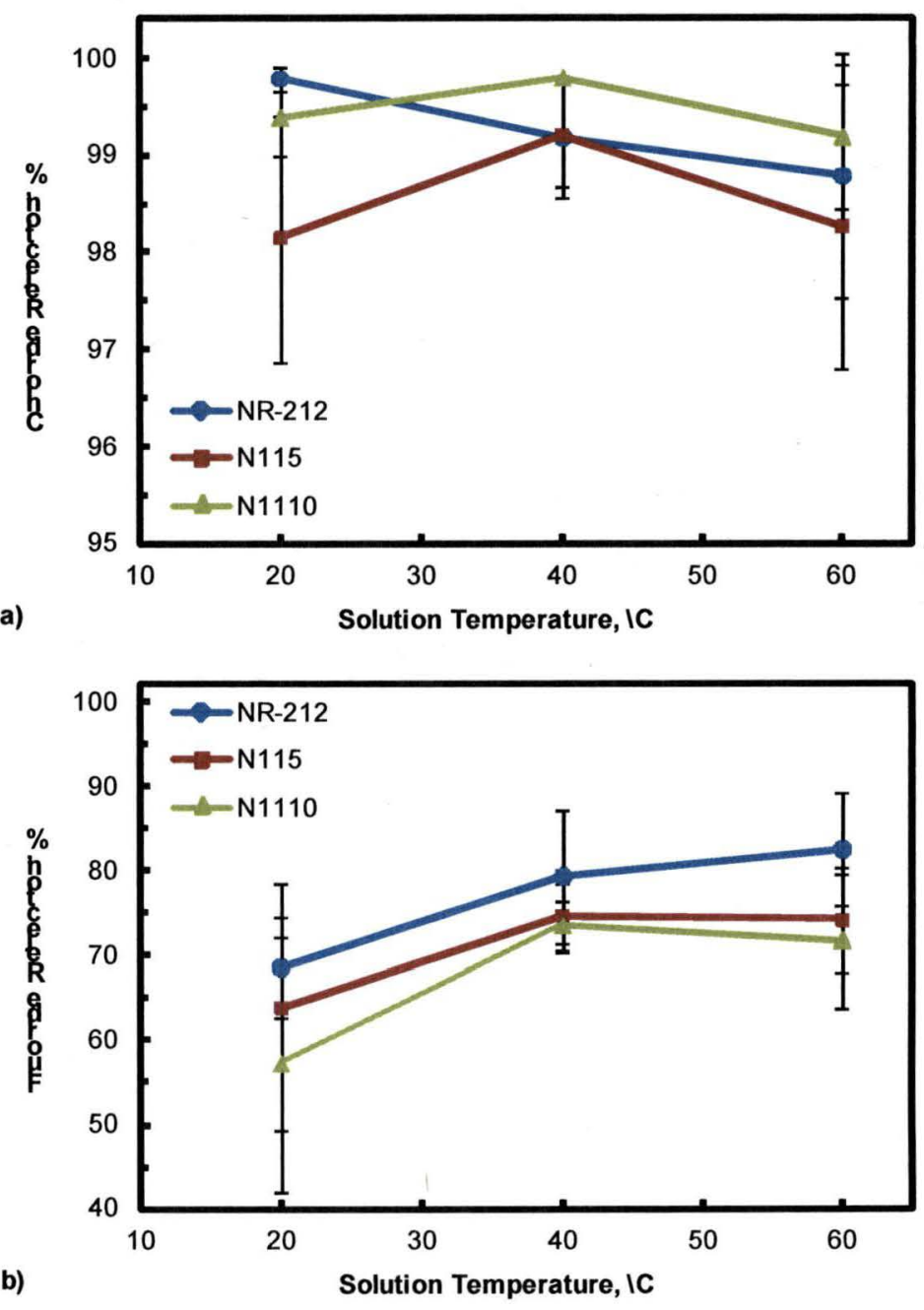

Figure 3. Anion rejection as a function of temperature and membrane thickness. The results show the fraction of chloride (a) and fluoride (b) rejected from a starting solution of $10000 \mathrm{ppm}$ each of $\mathrm{HCl}$ and $H F$. 


\section{Conclusion}

The permeation of water, fluoride and chloride for solutions of hydrochloric and hydrofluoric acids across Nafion membranes have been determined as a function of membrane thickness, gas flow rate, and acid solution temperature. Water permeation and fluoride rejection are both maximized across thinner membranes at higher temperatures and gas flow rates. Chloride permeation is very low under all conditions tested. These results have proven useful in optimizing the operating conditions of lab-scale ISRU water purification systems, and are being used to assist in the development of other unit operations to be used in conjunction with a Nafion membrane-based system.

\section{Acknowledgments}

The authors thank Bill Larson, ISRU Project Manager at Kennedy Space Center, and the Kennedy Graduate Fellowship Program for its support of this work.

\section{References}

${ }^{1}$ Torasso, A., "ISRU technologies and sustainable space exploration," AIAA $58^{\text {th }}$ International Astronautical Congress, 2007, pp. 7115-7127. 1762.

${ }^{2}$ Vallerani, E., "ISRU: Perspectives for lunar development," AIAA 57 International Astronautical Congress, 2006, pp. 1748-

${ }^{3}$ Hedge, U., Balasubramaniam, R., Gokoglu, S., "Analysis of thermal and reaction times for hydrogen reduction of lunar regolith," Space Technology and Applications International Forum, 2008, pp. 195-202.

${ }^{4}$ Maurice, S., Feldman, W.C., Lawrence, D.J., Gasnault, O., Elphic, R.C., Chevrel, S., "Distribution of hydrogen at the surface of the moon," Lunar and Planetary Science, Vol. 34, 2003, p. 1867.

${ }^{5}$ Schrader, C.M., Rickman, D.L., McLemore, C.A., Fikes, J.C., "Lunar Regolith Simulant User's Guide," NASA TM-2010$216446,2010$.

${ }^{6}$ Arda, M., Orhan, E., Arar, O., Yuksel, M., Kabay, N., "Removal of fluoride from geothermal water by electrodialysis," Separation Science and Technology, Vol. 44, 2009, pp. 841-853.

${ }^{7}$ Deng, S., Liu, H., Zhou, W., Huang, J., Yu, G., "Mn-Ce oxide as a high-capacity adsorbent for fluoride removal from water," Journal of Hazardous Materials, Vol. 186, 2011, pp. 1360-1366.

${ }^{8}$ Dou, X., Zhang, Y., Wang, H., Wang, T., Wang, Y., "Performance of granular zirconium-iron oxide in the removal of fluoride from drinking water," Water Research, Vol. 45, 2011 , pp. 3571-3578.

${ }^{9}$ Lu, N.C., Liu, J.C., "Removal of phosphate and fluoride from wastewater by a hybrid precipitation-microfiltration process," Separation and Purification Technology, Vol. 74, 2010, pp. 329-335.

${ }^{10}$ Miretzky, P., Cirelli, A.F., "Fluoride removal from drinking water by chitosan derivatives and composites: A review," Journal of Fluorine Chemistry, Vol. 132 (2011), pp. 231-240.

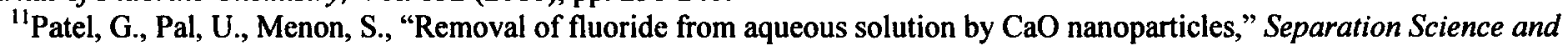
Technology, Vol. 44, 2009, pp. 2806-2826.

${ }^{12}$ Sun, Y., Fang, Q., Dong, J., Cheng, X., Xu, J., "Removal of fluoride from drinking water by natural stilbite zeolite modified with Fe(III)," Desalination, Vol. 277, 2011, pp. 121-127.

${ }^{13}$ Majsztrik, P.W., Satterfield, M.B., Bocarsly, A.B., Benziger, J.B., "Water sorption, desorption and transport in Nafion membranes," Journal of Membrane Science, Vol. 301, 2007, pp. 93-106.

${ }^{14}$ Schmidt-Rohr, K., Chen, Q., "Parallel cylindrical water nanochannels in Nafion fuel-cell membranes," Nature Materials, Vol. 7, 2008, pp. 75-83.

${ }^{15}$ Unnkrishnan, E.K., Kumar, S.D., Maiti, B., "Permeation of inorganic anions through Nafion ionomer membrane," Journal of Membrane Science, Vol. 137, 1997, pp. 133-137.

${ }^{16}$ Helffierich, F., Ion Exchange, McGraw-Hill, 1962, pp. 134-147.

${ }^{17}$ Wade, L.G., Organic Chemistry, $4^{\text {th }}$ Ed., Prentice-Hill, 1999, p. 25. 

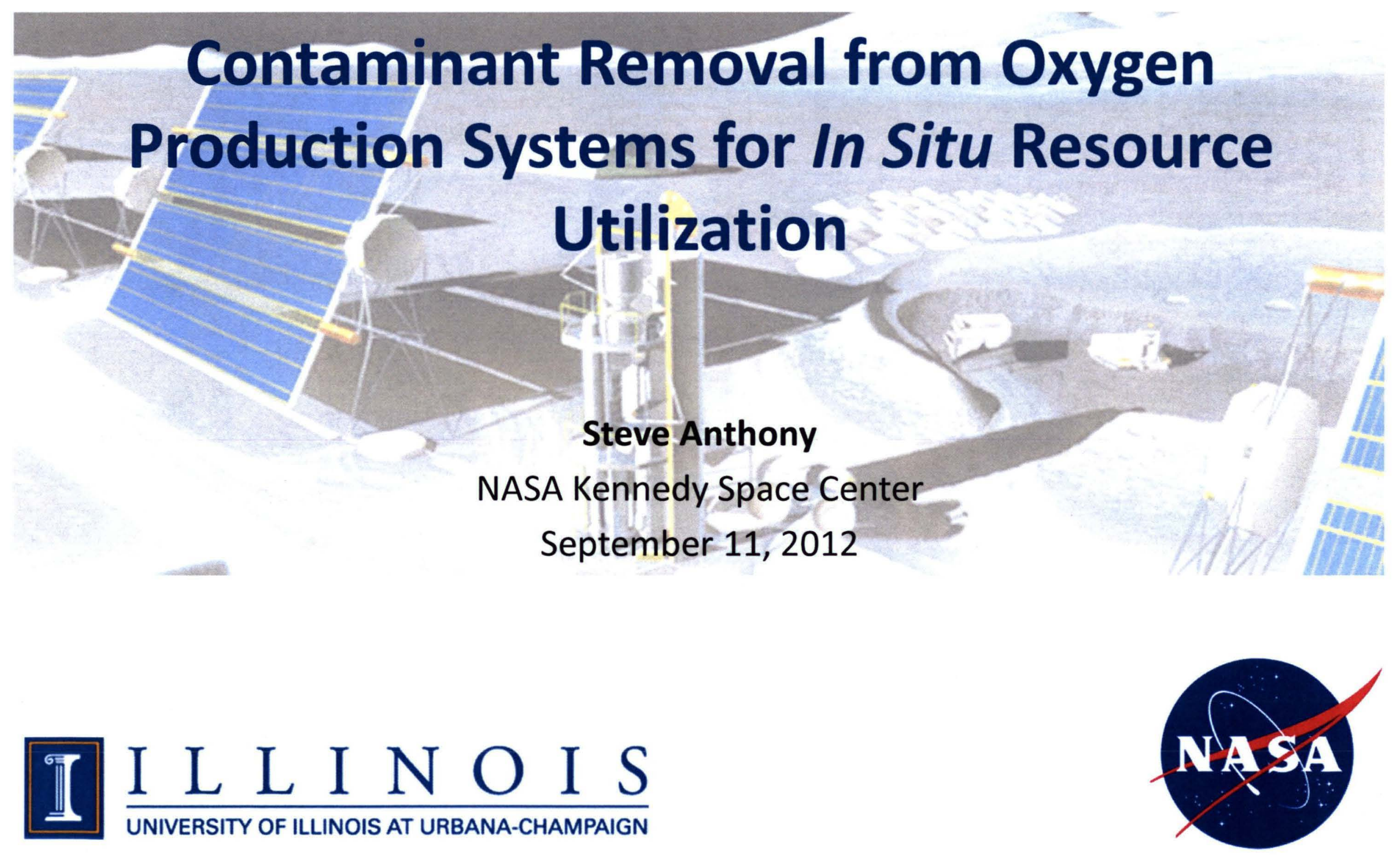


\section{In Situ Resource Utilization}

- One of NASA's goals is to enable long-term human presence in space, without the need for continuous replenishment of consumables from Earth.

- In situ resource utilization (ISRU) is the use of extraterrestrial resources to support activities such as human life-support, material fabrication and repair, and radiation shielding.

- Potential sources of ISRU resources include lunar and Martian regolith (soil), and Martian atmosphere.

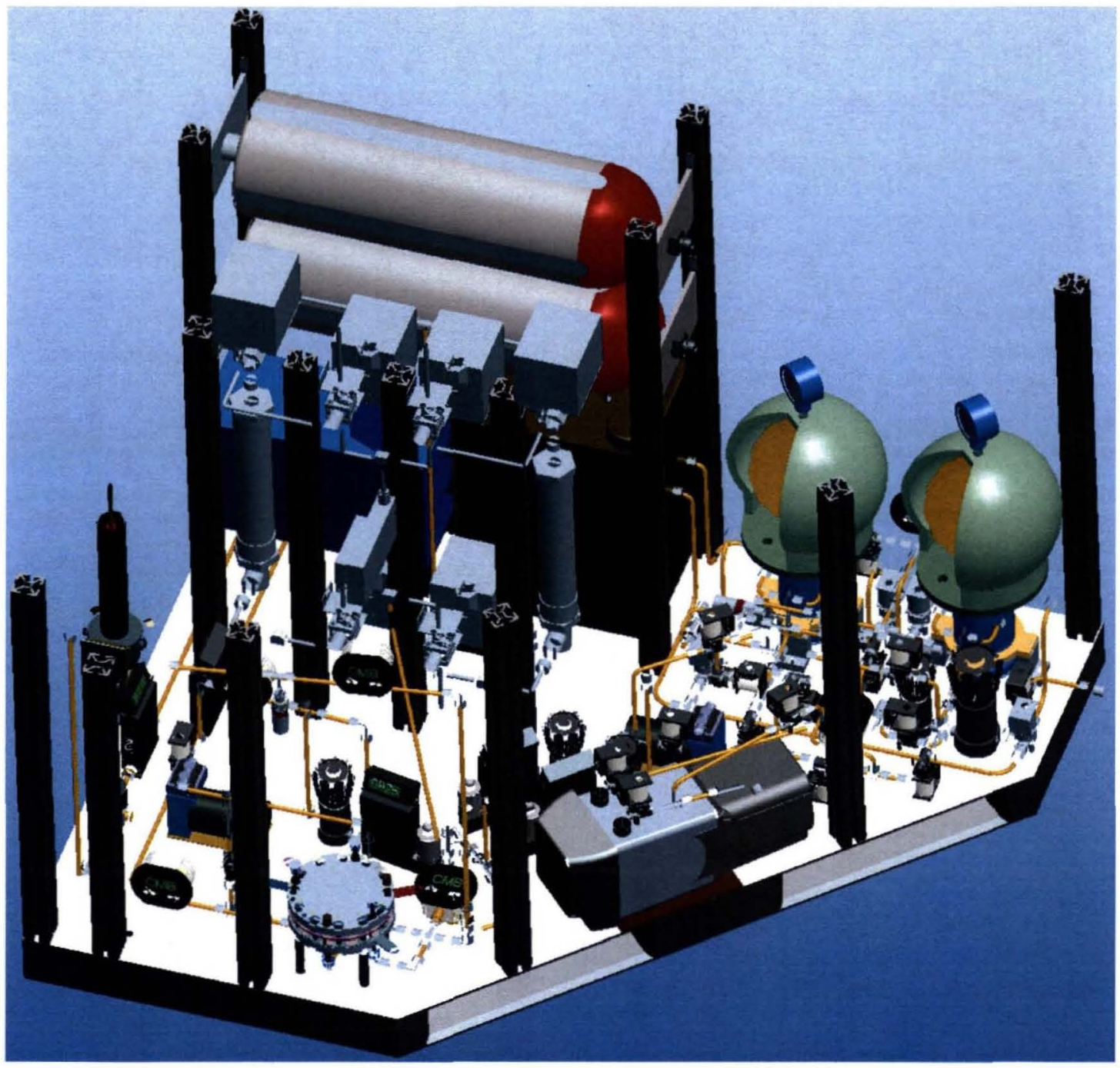

MARCO POLO Mars Atmospheric Carbon Dioxide Capture System 


\section{Composition of Lunar Regolith}

- Oxygen and metals found in lunar regolith may be mined for rocket propellant, life support and construction materials.

- Lunar regolith is composed of elements and minerals in ratios very similar to that of terrestrial soil and rock:

- Elemental composition: $40+\% \mathrm{O}, 20 \% \mathrm{Si}, 12 \% \mathrm{Fe}, 8.5 \% \mathrm{Ca}, 7.3 \% \mathrm{Al}, 4.8 \% \mathrm{Mg}, 4.5 \% \mathrm{Ti}$.

- Hydrogen is present at the poles due to water from asteroid and comet impacts that becomes trapped in permanently-shaded craters.

- The regolith contained in these basins is basaltic (primarily feldspar, pyroxine, and olivine).

- Average compostion of Apollo mission soil samples:

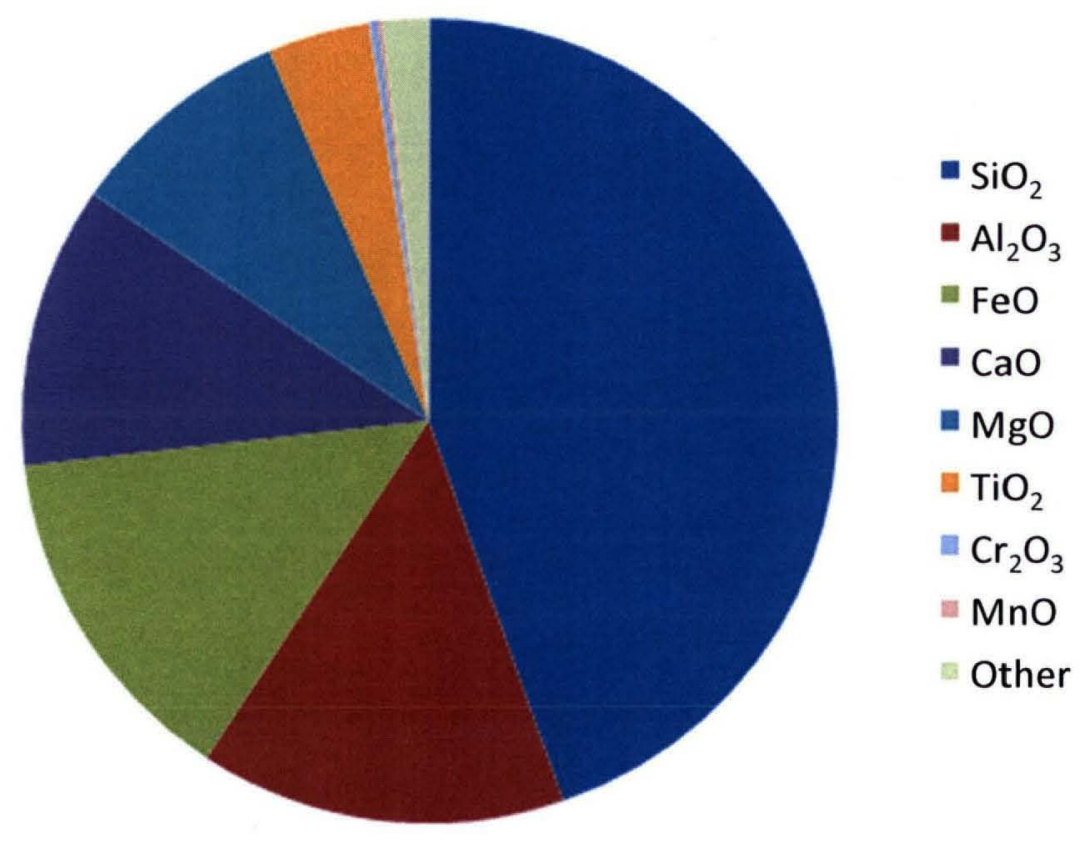




\section{Water and Oxygen Production from Lunar Regolith}

- One focus of the Regolith and Environment Science and Oxygen and Lunar Volatile Extraction (RESOLVE) project is the extraction of water and oxygen from hydrogen-rich lunar regolith.

- Water and byproducts (including hydrochloric and hydrofluoric acids) are extracted from lunar regolith via a hightemperature hydrogen reduction reaction and passing the produced gas through a condenser.

$$
\mathrm{FeO}+\mathrm{H}_{2} \stackrel{\mathrm{Fe}}{\rightarrow}+\mathrm{H}_{2} \mathrm{O}
$$

- Due to the high solubility of $\mathrm{HCl}$ and $\mathrm{HF}$ in water, these byproducts are expected to be present in the product stream ( 20000 ppm) and must be removed ( $<10 \mathrm{ppm})$ prior to water consumption or electrolysis.

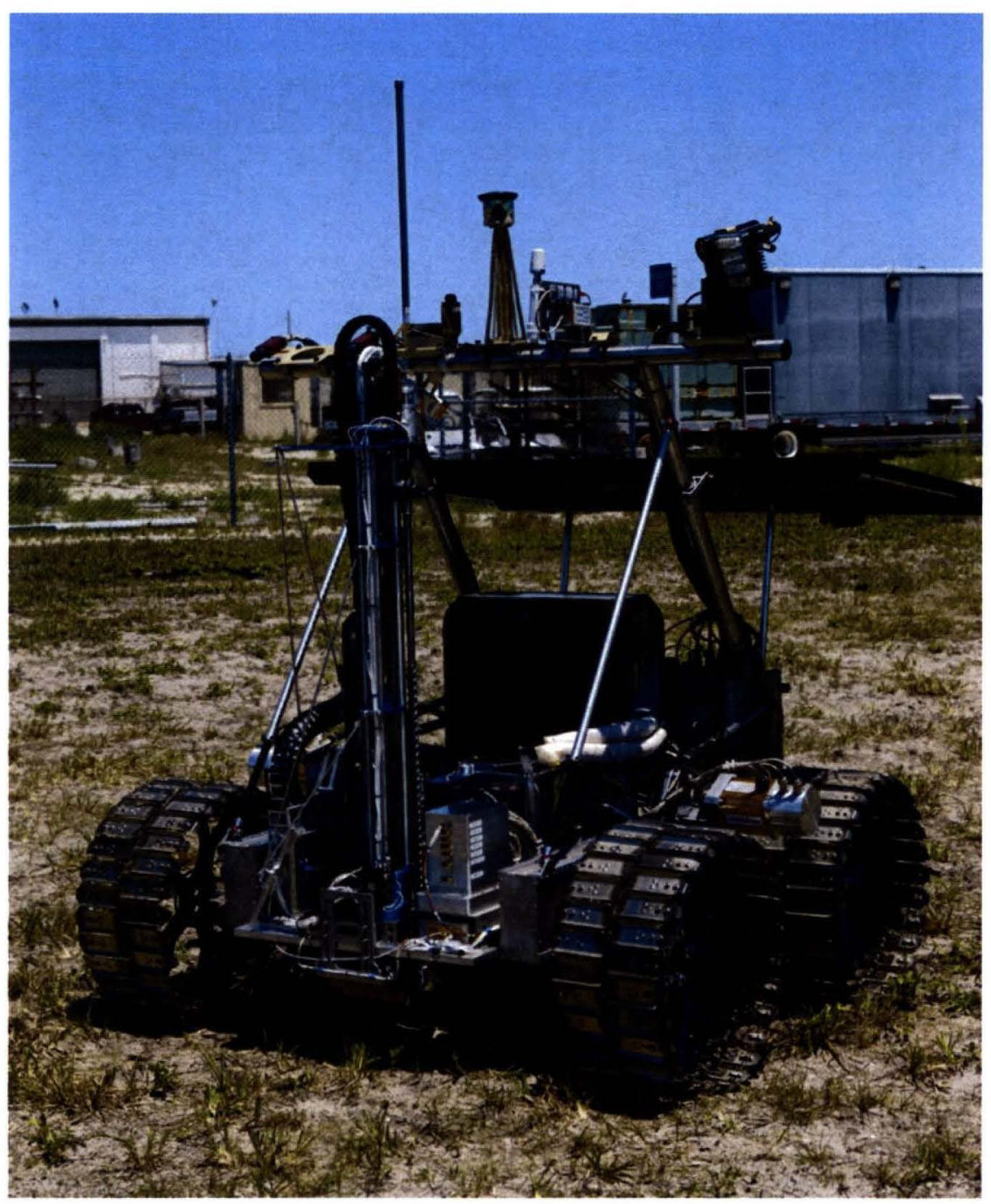

RESOLVE Rover and Chemistry Lab Prototype http://www.nasa.gov/exploration/systems/ground/resolverover.html 


\section{Halide Removal Techniques}

- Due to their consumable nature, typical water purification methods may not be suitable for $\mathrm{HCl}$ and $\mathrm{HF}$ removal in extraterrestrial applications.

- Membranes and adsorbents are often regenerated with large amounts of water and/or basic solutions, which aren't available in the lunar environment.

- Naturally-occurring adsorbents may be replaced rather than regenerated.

\begin{tabular}{|c|c|}
\hline Method & Examples \\
\hline $\begin{array}{c}\text { Membrane } \\
\text { (solute retention) }\end{array}$ & Reverse osmosis \\
Membrane \\
(solute transport) & Nanofiltration \\
\hline Adsorption & Dialysis \\
\hline
\end{tabular}




\section{Nafion Membranes for Contaminant Reduction}

- Nafion, a sulfonated tetrafluoroethylene polymer, is commonly used as a fuel cell proton exchange membrane.

- Due to its high proton and low anion conductivities, Nafion is desirable as a filtration membrane for anion contaminant removal.

- Nafion membranes reject anions via charge exclusion, and do not require regeneration.

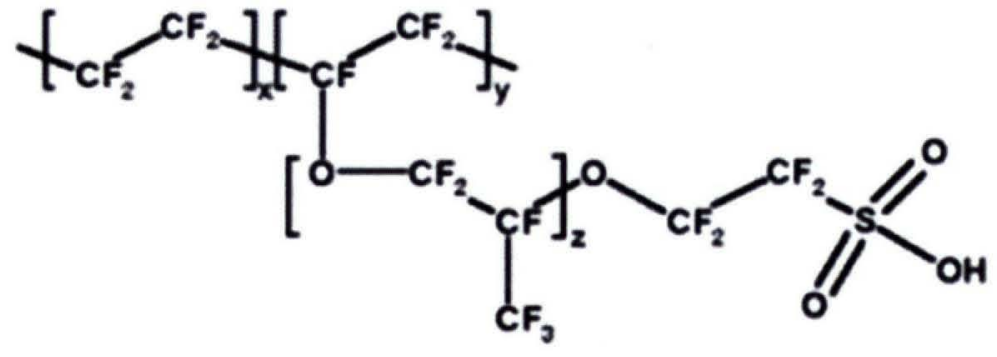

Chemical structure of Nafion

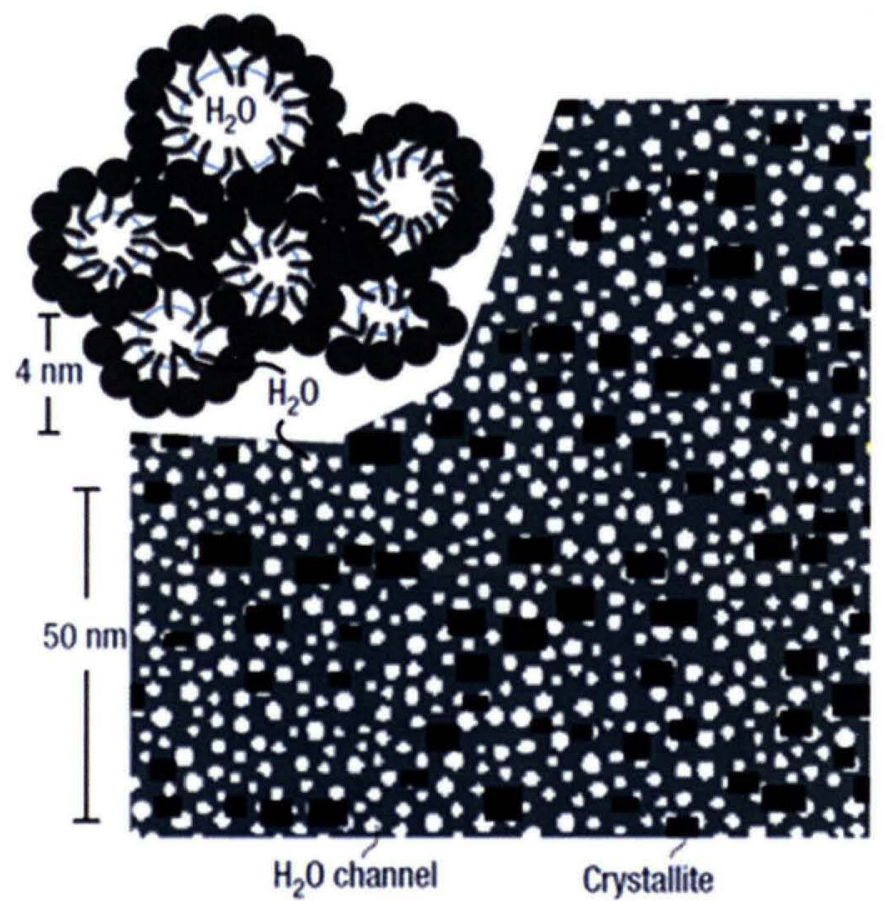

Nafion water channel model

Schmidt-Rohr et al., Nature Materials 7 (2008) 


\section{Water Transport Across Nafion Membranes}

- Nafion's sulfonic acid end groups form negatively-charged water channels through which small molecules can pass
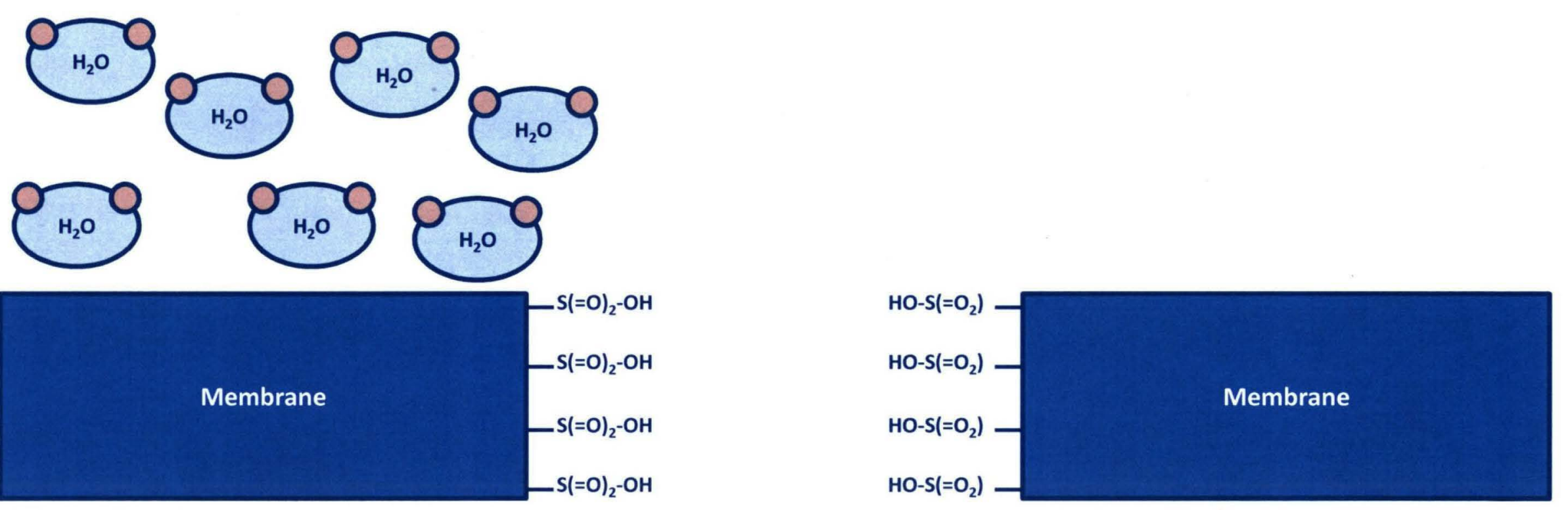


\section{Chloride Transport Across Nafion Membranes}

- Strong acids such as $\mathrm{HCl}$ fully dissociate in water and are not expected to permeate across a Nafion membrane
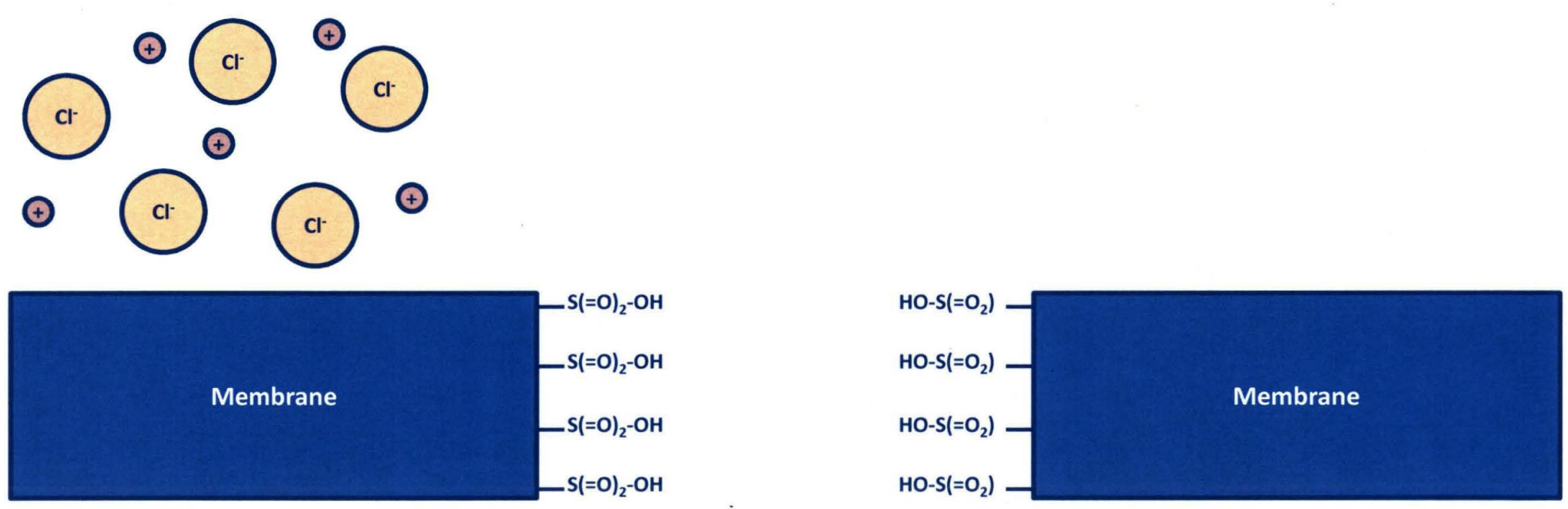


\section{Fluoride Transport Across Nafion Membranes}

- Weak acids such as HF do not fully dissociate in water and are expected to permeate across a Nafion membrane
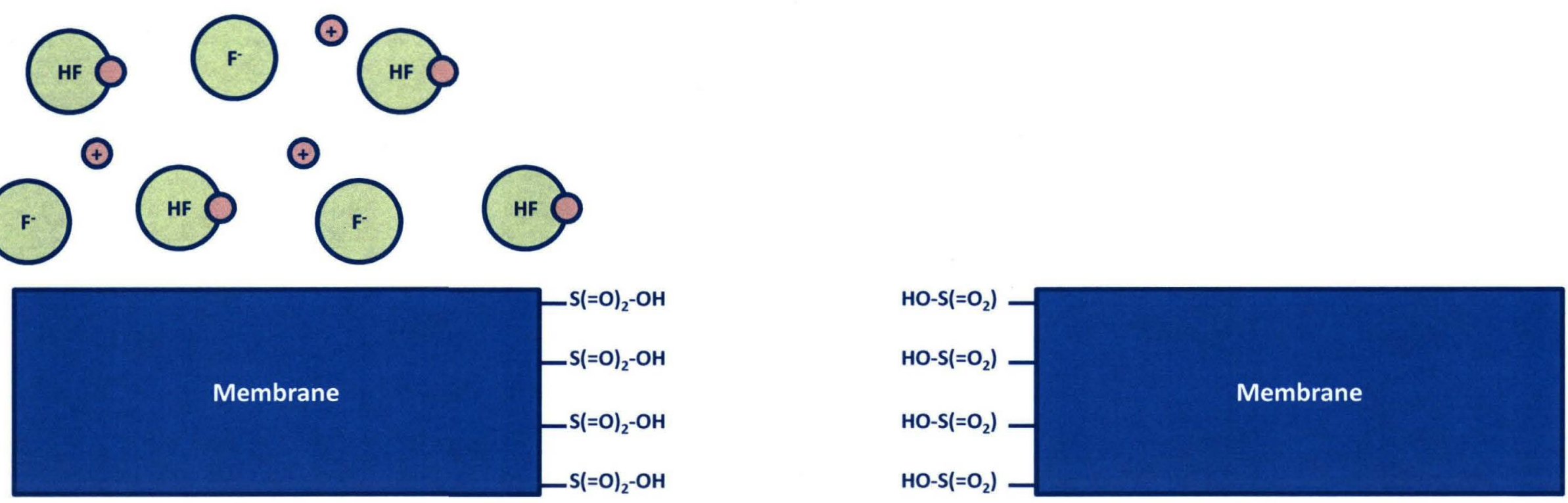


\section{Experimental Apparatus}

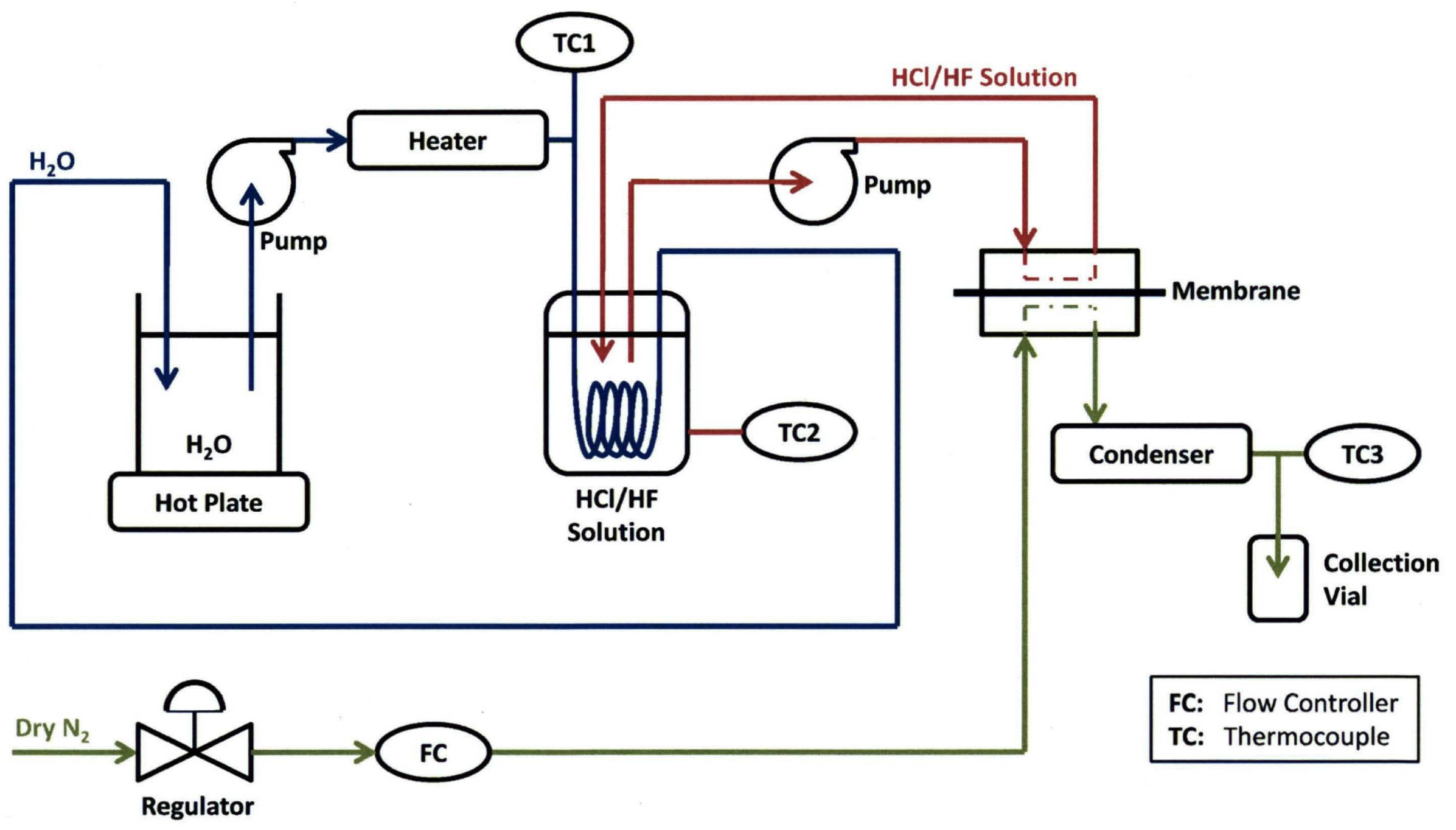



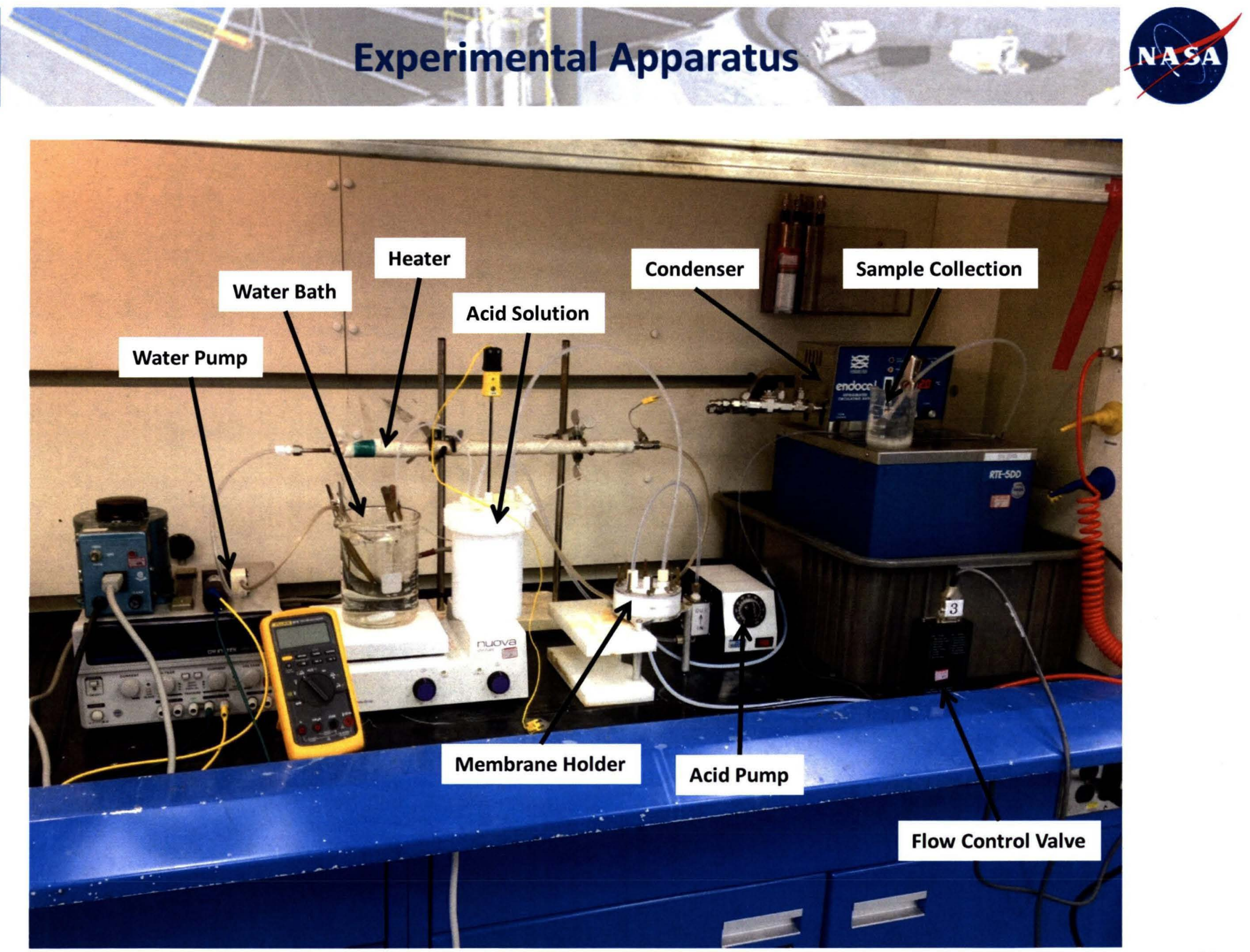


\section{Calculating Water Flux and Halide Rejection}

- Water flux $\left(J_{w}\right)$ is a function of the mass of water $(m)$ that diffuses across the membrane cross-sectional area $(A)$ over time $(t)$.

- Calculated water flux accounts for water that diffuses across the membrane but remains in vapor form at the condenser outlet, using the vapor pressure of water $(p)$ at temperatures at the membrane $\left(T_{m}\right)$ and the condenser outlet $\left(T_{c}\right)$.

$$
J_{w}=\frac{m}{A \cdot t} \cdot \frac{p\left(T_{m}\right)}{p\left(T_{m}\right)-p\left(T_{c}\right)}
$$

- Anion rejection $\left(R_{i}\right)$ is defined as the mass fraction of fluoride or chloride that does not diffuse across the membrane.

- Anion concentration on the liquid $\left(C_{i}^{L}\right)$ and gas $\left(C_{i}^{G}\right)$ of the membrane was determined using ion chromatography.

$$
R_{i}=1-\frac{C_{i}^{G}}{C_{i}^{L}}
$$




\section{Water Flux Across Nafion Membranes: Effect of Membrane Thickness, Gas Flow Rate, and Solution Temperature}

- Increasing gas flow rate likely increases water concentration gradient across membrane, resulting in higher water flux.

- Increasing solution temperature likely swells membrane water channels, which increases water flux.

- In agreement with Fickian diffusion, increasing membrane thickness reduces water flux.

- Efficiency of water flux (mass of water transferred per unit volume of gas) decreases with increasing gas flow rate. This may be due to higher gas flow rates cooling the gas side of the membrane.
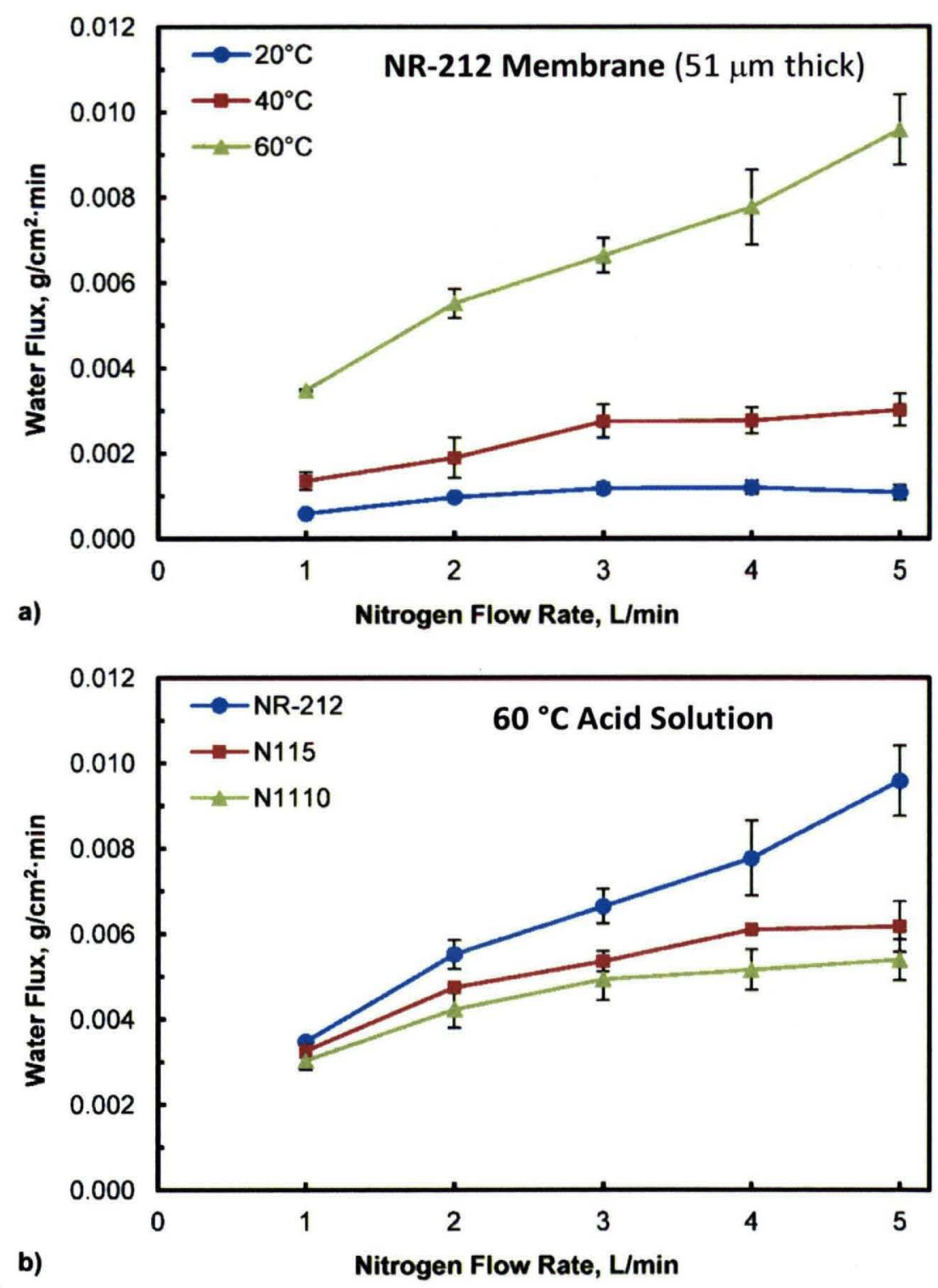


\section{TI Acid Rejection By Nafion Membranes: \\ Effect of Membrane Thickness and Solution Temperature}

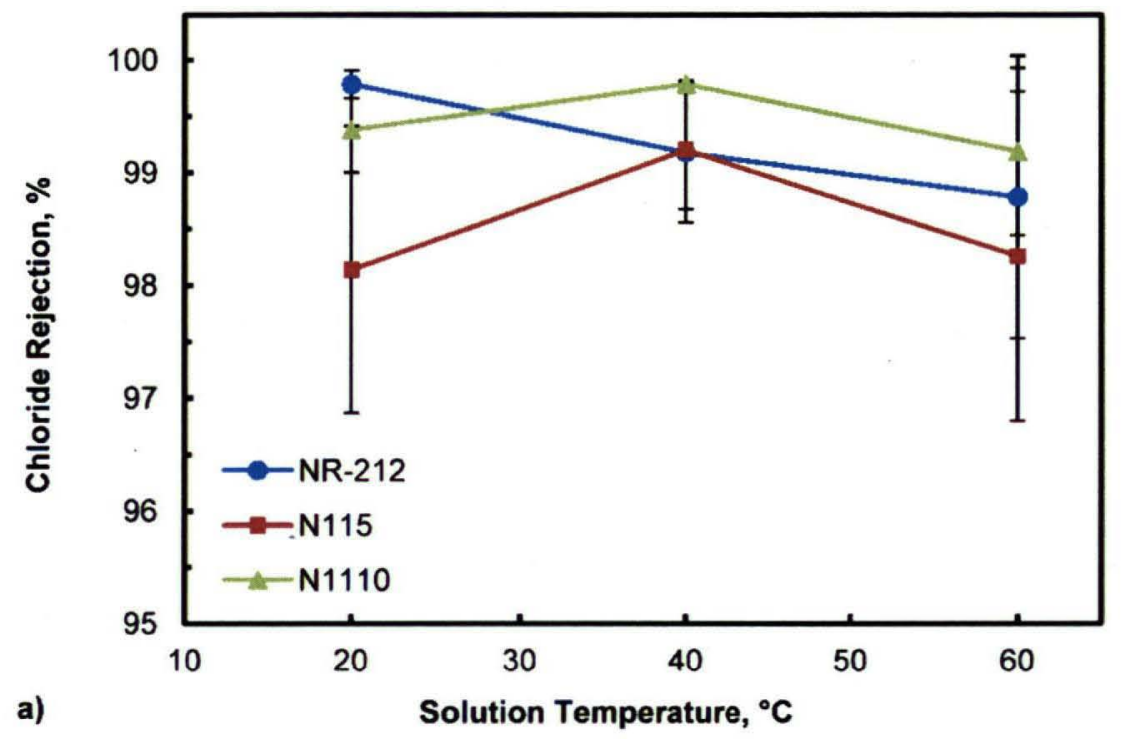

- Gas flow rate has no effect on chloride and fluoride rejection.

- Chloride rejection is very high (>95\%) at all gas membrane thicknesses and temperatures, while fluoride rejection is much lower (55-85\%).

- Swelling of water channels at higher temperatures may lead to higher concentration of surface sulfonic acid groups, which increases the negative

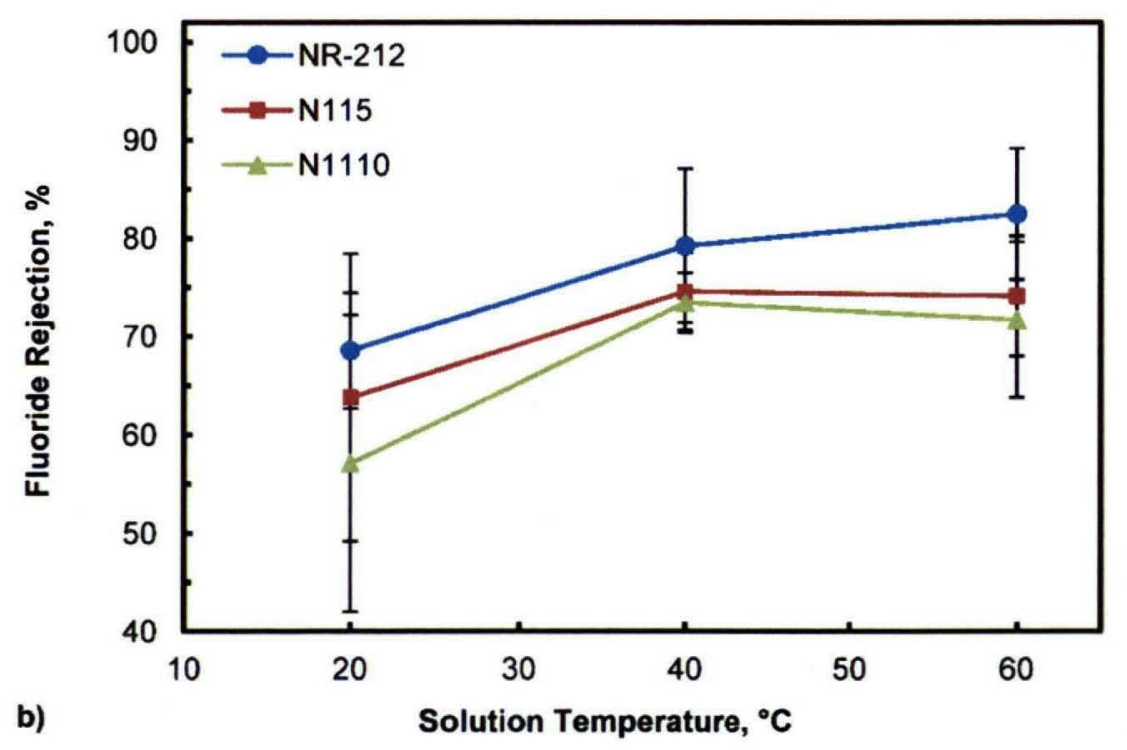
potential across the membrane and improves fluoride rejection.

- Less efficient proton diffusion out of water channels of thicker membranes may decrease the negative potential across the membrane, worsening fluoride rejection. 


\section{Developing an In Situ Filtration System for Acid Removal}

- Nafion alone is not able to provide adequate chloride and fluoride rejection.

- Fluoride removal may be enhanced by passing the product stream:

- Through multiple membranes in series.

- Through an adsorbent suspension.

- Over an anion exchange membrane.

- A pre-treatment step should precede Nafion membrane filtration

- Passing the solution through multiple Nafion membranes in series increases acid rejection, but greatly reduces water yield.

- Addition of adsorbent suspension prior to Nafion membrane filtration should increase acid removal from product stream but will require replacement or regeneration.

- Passing the solution over an anion exchange membrane (e.g., electrodialysis) should decrease acid concentration in feed stream, but disposal of resulting waste stream will be required.
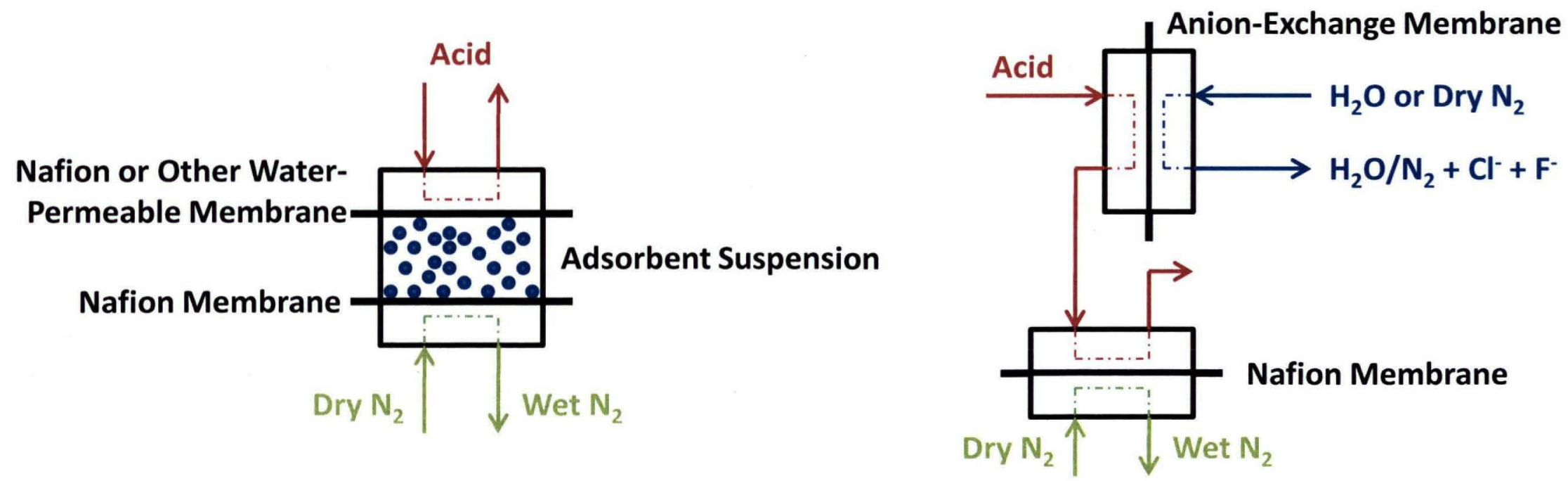

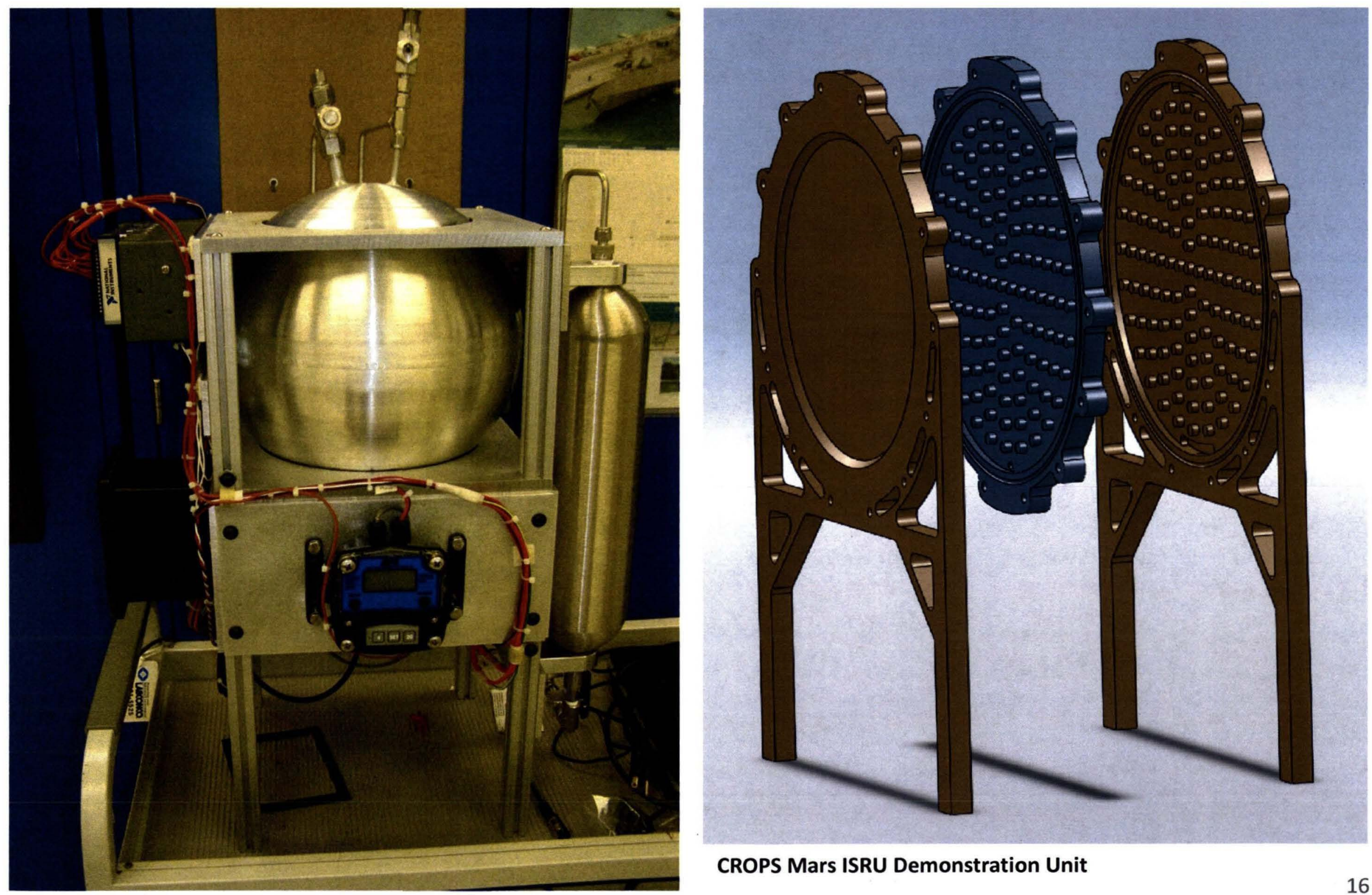


\section{Acknowledgements}

\section{Collaborators}

- Edgardo Santiago-Maldonado, NASA Kennedy Space Center

- Jim Captain, Qinetiq North America

- Dr. Scott Jolley, Qinetiq North America

- Dr. Ashtamurthy Pawate, University of Illinois at Urbana-Champaign

- Prof. Paul Kenis, University of Illinois at Urbana-Champaign

\section{Funding Sources}

- Bill Larson, KSC ISRU Project Manager

- Kennedy Graduate Fellowship Program

- KSC Center Innovation Fund

- KSC Independent Research and Technology Development Fund 


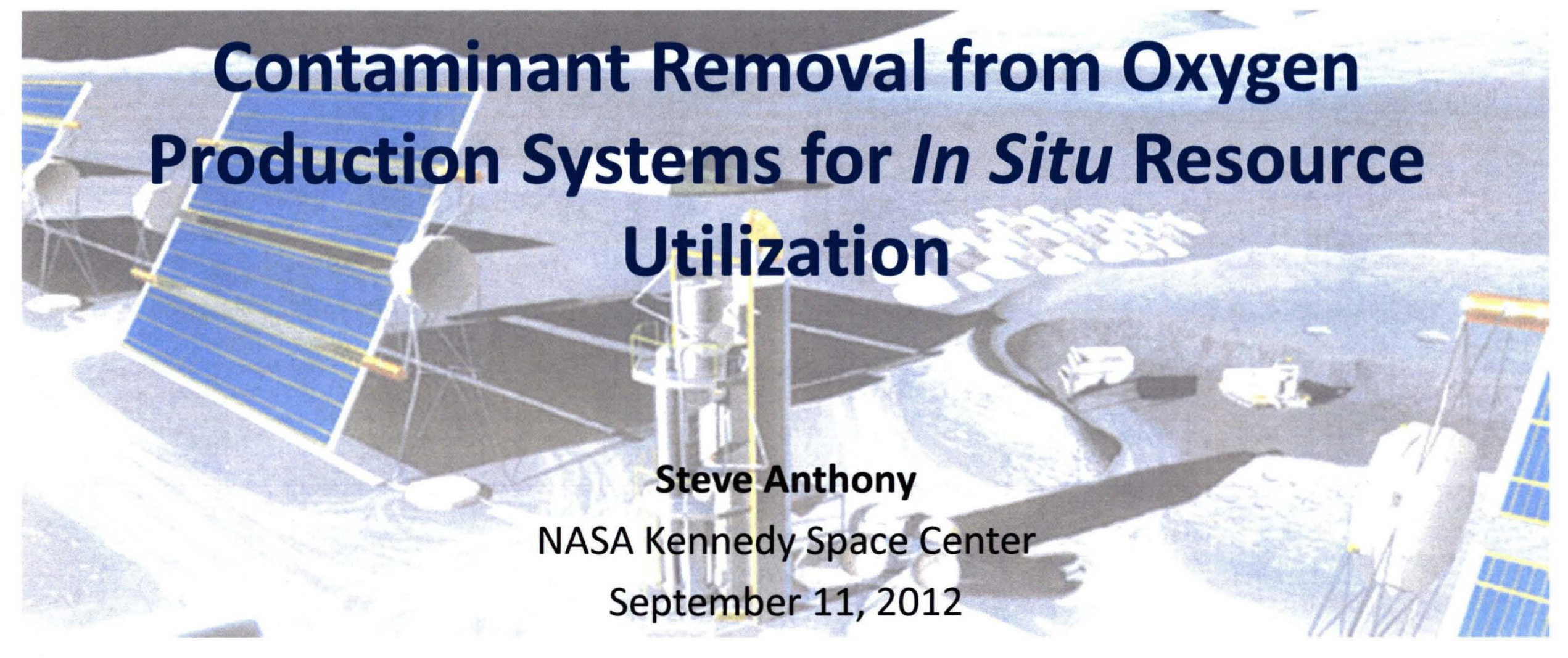

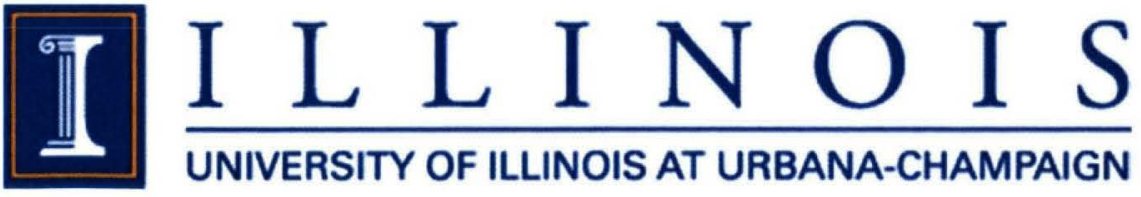

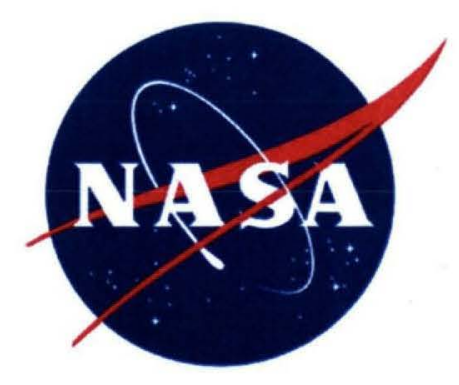

